\title{
Soil Plasticity Model for Analysis of Collapse Load on Layers Soil
}

\author{
Masyitah Md Nujid ${ }^{1, a}$ and Mohd Raihan Taha ${ }^{1}$ \\ ${ }^{1}$ Department of Civil Engineering and Structural Engineering, Universiti Kebangsaan Malaysia, 43650 Bangi, \\ Selangor, Malaysia
}

\begin{abstract}
Natural soil consist of soil deposits which is a soil layer overlying a thick stratum of another soil. The bearing capacity of layered soil studies have been conducted using different approach whether theoretical, experimental and combination of both. Numerical method in computer programme has become a powerful tool in solving complex geotechnical problems. Thus in numerical modelling, stress-strain soil behaviour is well predicted, design and interpreted using appropriate soil model. It is also important to identify parameters and soil model involve in prediction real soil problem. The sand layer overlaid clay layer soil is modelled with Mohr-Coulomb and Drucker-Prager criterion. The bearing capacity in loaddisplacement analysis from COMSOL Multiphysics is obtained and presented. In addition the stress distribution and evolution of plastic strain for each thickness ratio below centre of footing are investigated. The results indicate the linear relation on load-displacement which have similar trend for both soil models while stress and plastic strain increase as thickness ratio increase.
\end{abstract}

\section{Introduction}

Layered soil may consist of soil deposits which is a soil layer on top or called surface layer of finite thickness overlying a thick stratum of another soil. A homogeneous soil layer is considered if depth from footing base on top layer to lower layer $\mathrm{H}_{\mathrm{o}}$ approximately in Equation (1).

$$
\mathrm{H}_{\mathrm{o}}=0.5 \mathrm{~B} \tan (45+\phi / 2)
$$

where $\mathrm{B}$ is a width of shallow footing and $\phi$ is internal friction angle. In practice it is usually assumed that $\mathrm{H}=2 \mathrm{~B}$ The ultimate bearing capacity equation in Equation (2) for a strip footing in a uniform soil states that,

$$
q_{u}=c N c+\gamma D N q+1 / 2 B \gamma N \gamma
$$

where $\mathrm{q}_{\mathrm{u}}=$ ultimate bearing capacity $\left(\mathrm{kN} / \mathrm{m}^{2}\right) ; \mathrm{c}=$ cohesion; $\gamma=$ effective unit weight $\left(\mathrm{kN} / \mathrm{m}^{3}\right)$; $\mathrm{B}=$ width of the footing (m); D = depth of embedment (m); and $\mathrm{N}_{\mathrm{c}}, \mathrm{N}_{\gamma}$ and $\mathrm{N}_{\mathrm{q}}=$ bearing capacity factors,

\footnotetext{
${ }^{\text {a }}$ Corresponding author : masyitahnujid@gmail.com
} 
which are a function of the effective stress friction angle $\phi$. In Equation (2) indicates that $q_{u}$ increases linearly with B or D. Also few assumptions are taken such that $\phi$ and $\gamma$ are constant with depth and the soil is dry. Thus for effective soil which shear strength increase linearly with depth at failure is expressed in Equation (3).

$$
\tau_{f}=c+\sigma_{n}^{\prime} \tan \phi^{\prime}
$$

However the bearing capacity of layered soils cannot be treated anymore as single soil since the soil strength and stiffness parameters are differ or increase linearly with depth. In present day numerical analysis such as finite element difference and finite element method using appropriate constitutive equation become a powerful technique in geotechnical problems to analyze complex behavior of stress and strain due to external loading and geometrical such as multiple layers of soil [1, $5,7]$. Several studies on load-deformation relation of shallow foundation by numerical analysis were conducted using von Mises, Mohr Coulomb (MC) and Drucker-Prager (DP) criterion due to some limitations in finite element package. However the constitutive soil models (von Mises, MC and DP) incapable to model certain cases of problem such as stress path dependency and coupling of volumetric and shear response [2, 4, 6].

In present study, this paper is attempted to implement soil plasticity models which are MohrCoulomb and Drucker-Prager models for bearing capacity of strip footing on layered soil. The bearing capacity is presented in load-displacement analysis which is obtained from COMSOL Multiphysics finite element package. The behavior of layered soil under strip footing is also being analyzed. In addition this paper will look into factor of thickness ratio which govern the development of stress behavior of layered soil under strip footing.

\section{COMSOL Multiphysics}

The COMSOL Multiphysics finite element software offers real simulation problems with partial differential equation applied in the software with elements of multiphysics such as heat, particle tracing and water flow. In this study there are two branches have been selected: 1) Solid Mechanics; Geomechanic and 2) Mathematics; ODE and DAE. Normally the processes of numerical simulation involve with assigning geometry, material, physic branch, mesh, analyze and viewing result [8]. The bearing capacity is obtained from load-displacement curve and similar geotechnical problem using this software i.e [9]. The study analysis is done in function of thickness ratio and properties of soils are remain constant throughout the analysis.

\section{Constitutive Soil Model}

By assuming the footing problem in plane strain condition and the foundation is treated as an elasticperfectly plastic material. Before yielding within the elastic range, the stress-strain relationship of the soil is described by Hooke's law. Beyond the elastic range, the soil is assumed to behave as perfectly plastic in accordance with Mohr-Coulomb and Drucker-Prager (extended Von Mises) yield criterion. In COMSOL Multiphysics (v4.4) programme these two models were chosen to be used in analysis.

\subsection{Mohr-Coulomb model}

The simplest and controversial constitutive soil model is Mohr-Coulomb which accepted in geotechnical problems due to simplicity to define soil parameters. The strength of soil mass using the simple elastic-perfectly plastic model requires cohesion (c) and internal angle of friction $(\phi)$.

For simple elasto-plastic soil plasticity obey Mohr-Columb yield criterion in plane strain deformation, 


$$
f(\sigma)=0
$$

where Equation (4) in principal stresses space,

$$
f(\sigma)=\frac{1}{2}\left(\sigma_{\max }-\sigma_{\min }\right)+\frac{1}{2}\left(\sigma_{\max }+\sigma_{\min }\right) \sin \phi-c \cos \phi=0
$$

where $\sigma_{\max }$ and $\sigma_{\min }$ are the biggest and smallest principal stresses. The Mohr-Coulomb criterion defines an irregular hexagon pyramid in the prinsipal stress space which give rise to singularities in the derivatives of the yield function.

\subsection{Drucker-Prager model}

The Drucker-Prager model approximate the Mohr-Coulomb criterion by a circle on the cross-sectional shape of the yield surface by a smooth function based on the invariant $I_{1}$ and $J_{2}$ together with two material constants. The yield surface for the Drucker-Prager criterion is given by,

$$
f=\alpha I_{1}+\sqrt{J_{2}}=k=0
$$

In which $I_{1}$ and $J_{2}=$ the first stress invariant and the second stress invariant respectively; and $\alpha$ and $\mathrm{k}$ $=$ constants which are functions of strength parameters of the test soil and has two material constants for the plane strain condition can be expressed as follows,

$$
\alpha=\frac{\tan \phi}{(9+12 \tan \phi)^{1 / 2}}
$$

and

$$
k=\frac{3 c}{(9+12 \tan \phi)^{1 / 2}}
$$

The flow rule relation between the plastic strain increment in a given direction and the current level of stress in the same direction reads as,

$$
d \varepsilon_{i j}=d \lambda \frac{\partial Q}{\partial \sigma_{i j}}
$$

Where $d \lambda$ is the plastic multiplier and $Q$ is the plastic potential. If the yield surface $f$ and $Q$ are identical then it is called an associated flow rule and in oppose is called non-associated flow rule.

\section{Geomatry of Layered Soils, Soils Properties, Boundary Condition and Mesh Discretization}

Geometry of layered soils in numerical modelling was modelled in two dimensional (2D), plane strain problem with z-axis and footing was founded on surface of elastic half space soil (infinite element). In this analysis a flexible and smooth strip footing carried a vertical load on sand (Layer 1) overlaid clay (Layer 2) with static response. An infinite layer was drawn on the right side of the model to indicate 
flexible layer. Figure 1 shows geometry of layered soils in modelling where width of footing $\mathrm{B}=$ $1.0 \mathrm{~m}$. In order to consider effect of thickness ratio between top and bottom layers in layered soil, thickness of top layer, $\mathrm{h}$ play a vital role to indicate whether soil is homogeneous or inhomogeneous. If $\mathrm{h}<\mathrm{B}$ the soil is inhomogeneous and $\mathrm{h}>\mathrm{B}$ the soil is homogeneous. The physical and mechanical parameters of layered soils (i.e $\gamma, \nu, \mathrm{E}, \phi, \Psi$ ) are given in Table 1. The properties of soils are remain constant throughout the analysis.

The finite element solutions were affected by selection boundary conditions and mesh refinement and size. Since the layered soil was symmetrical in geometry thus only half of it was modelled and assigned a prescribed displacement at nodes to the right of centerline. The bottom of the geometry model was assigned by a fixed end boundary condition. The right vertical boundary was perfectly smooth and a roller was assigned on right of the geometry problem (Figure 1). For non-uniform mesh discretization, coarse element mesh would be assigned at bottom, left and right sides of soil geometry model. Under footing base, the soil element would be discretized into medium fine and near at edge of footing, it was very fine mesh because of significant displacement change in this region. The element sizes affect the finite element solution where divergence could occur at very small size but require larger computational time [5]. The finite element mesh has 3337 degrees of freedom solved.

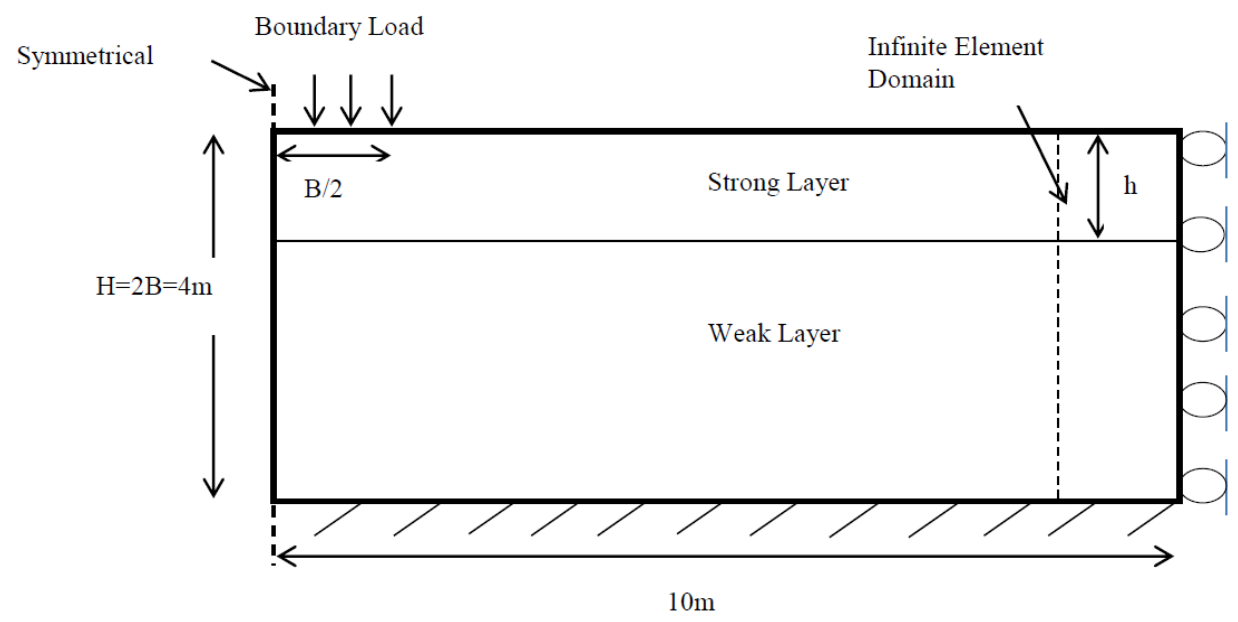

Figure 1. Geometry of layered soils model.

\section{Results and Discussion}

In Figure 2 show the load-displacement graphs for both Mohr-Coulomb and Drucker-Prager criteria. The graphs show that applied footing pressure versus the centerline displacement (directly beneath the footing's center) in the y direction. These graphs indicate similarity trend of footing pressure and displacement at beneath of footing's center for Mohr-Coulomb and Drucker-Prager criteria. By assuming that critical depth at $\mathrm{h}=2.0$ the footing pressure reached the collapse load at approximately 1.1 MPa. Figure 3(a) shows a linear relation between applied load and the displacement where an algebraic equation that controls the applied pressure so that the models reach the desired displacement increments. The desired vertical displacement in the analysis was $-0.05 \mathrm{~m}$ in Figure 3(b).

\subsection{Stress distribution}

At the desired vertical displacement $(0.05 \mathrm{~m})$ the von Mises stresses distribution show the value for each increment of thickness ratio (h/B) from 0.5 to 2.0 as in Table 2. In the table listed the stress distribution started at $0.561 \mathrm{MPa}(\mathrm{h} / \mathrm{B}=0.5)$, then dropped to $0.546 \mathrm{MPa}(\mathrm{h} / \mathrm{B}=1.0)$, increased to $0.559 \mathrm{MPa}(\mathrm{h} / \mathrm{B}=1.5)$ and finally at $\mathrm{h} / \mathrm{B}=2.0$ the stress distribution was $0.643 \mathrm{MPa}$. 


\subsection{Effect of thickness ratio on the analysis}

The load-displacement relation shows that the footing pressure increase linearly with thickness ratio from 0.5 to 2.0 with maximum footing pressure at beneath footing center was approximate $1.1 \mathrm{MPa}$. This was happened due to availability of ODE and DAE branch in COMSOL Multiphysics reached to desired vertical displacement at $0.05 \mathrm{~m}$ at maximum collapse loading. The soil plasticity models used indicate similarity trend for both Mohr-Coulomb and Drucker-Prager criterion which lied on single line. The capability offered in the Drucker-Prager model matched to Mohr-Columb model with existing two constant material parameters which related to strength of soil. This model overcome the limitation of Mohr-Coulomb model in yield criteria (Table 1). Meanwhile the stress distribution in von Mises showed the sudden dropped at thickness ratio of 1.0. However the difference still acceptable in range

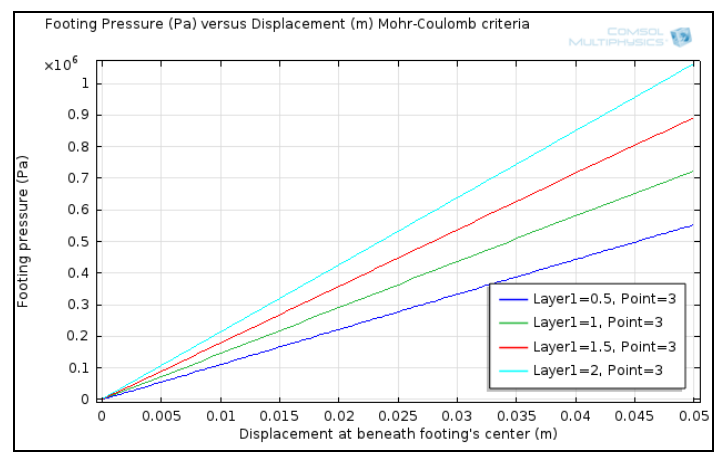

(a)

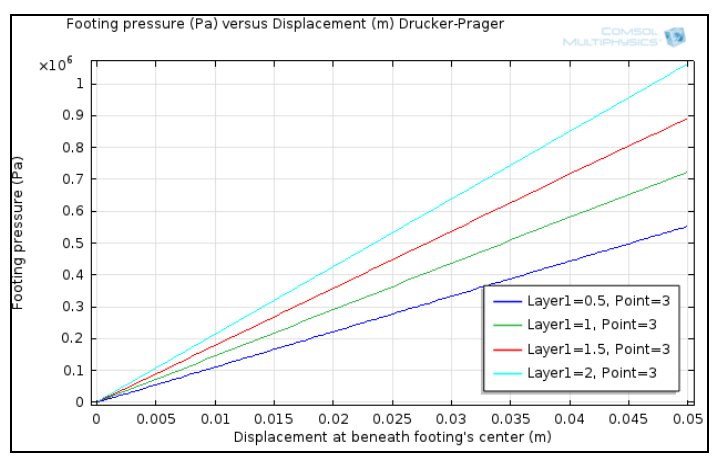

(b)

Figure 2. Load-displacement curve, (a) Mohr-Coulomb criteria and (b) Drucker-Prager criteria.

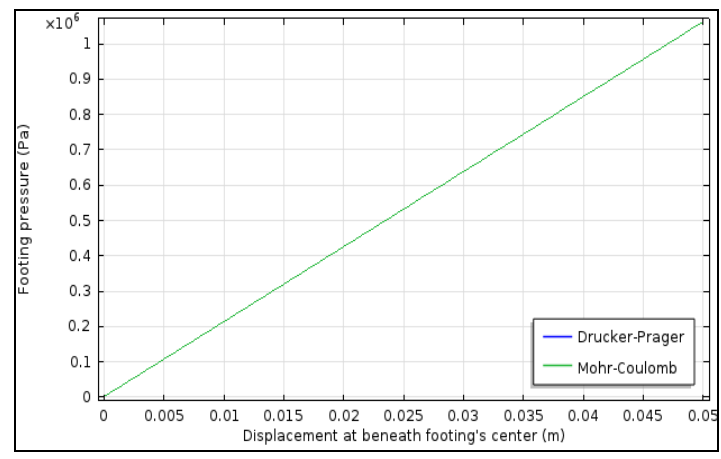

(a)

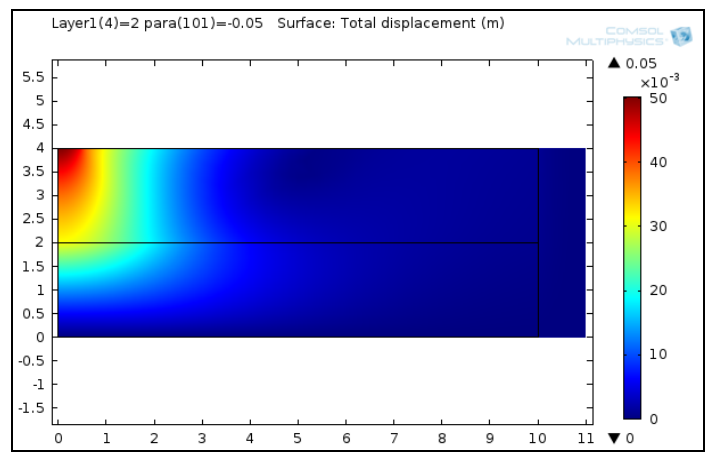

(b)

Figure 3. (a) Linear relation load-displacement, (b) total vertical displacement.

Table 1. Von Mises stress distribution at different thickness of layer 1.

\begin{tabular}{c|c}
\hline Thickness Ratio (h/B) & Stress Distribution (MPa) \\
\hline 0.5 & 0.561 \\
1.0 & 0.546 \\
1.5 & 0.559 \\
2.0 & 0.643 \\
\hline
\end{tabular}




\section{Summary}

The paper summarized and concluded effect of thickness ratio with implemented soil plasticity soil model on bearing capacity of strip footing on layered soil. Load-displacement relation showed linearly with desired vertical displacement for both Mohr-Coulomb and Drucker-Prager criterion on single line. The footing pressure increase as thickness ratio increase however stress distribution slightly drop at $\mathrm{h} / \mathrm{B}=1.0$ then continued to increment. It is important for geotechnical analysis using finite difference and finite element method for simulation in prediction real soil behavior on field with certain assumption in analysis for examples are geometry, boundary condition, discretization element and size. Besides choosing right solution of constitutive relation of stress and strain in soil model, it also could predict the real soil behavior itself and interaction with structures.

\section{Acknowledgement}

The first author would like to express gratefully acknowledgement to Ministry of Higher Education, Malaysia and Universiti Teknologi MARA for given a great opportunity in sponsoring the research study in the Geotechnical Engineering field.

\section{References}

[1] O.A. Abdulhafiz and A.A. Awad, Derivation on bearing capacity equation for a two layered system of weak clay layer overlaid by dense sand layer, Pertanika J. Sci. and Technol., 13(2), 213-235, (2005).

[2] A.H. Akhaveiss, Implementation of generalized plasticity in load- deformation behavior of foundation with emphasis on localization problem, World Academy of Science, Engineering and Technology, 39, 4-9, (2010).

[3] COMSOL Multiphysics v4.4, (2013).

[4] C.S.Desai, H.V. Phan and S. Sture, Procedure, selection and application of plasticity models for a soil, Int. J. Numer. Anal. Meth, Geomech., 5, 295-311, (1981).

[5] D.V. Griffiths, Computation of bearing capacity factors using finite elements, Geotechnique, 32(3), 195-202, (1982).

[6] J. Lee and R. Salgado, Estimation of bearing capacity of circular footings on sands based on cone penetration test, Journal of Geotechnical and Geoenvironmental Engineering, 131(4), 442-452, (2005).

[7] N. Maniharan and SP. Dasgupta, Bearing capacity of surface footings by finite elements, Computers and Structures, 54(4), 563-586, (1995).

[8] J. Mwebesa, D. Kalumba and R. Kulabako, Stimulating bearing capacity failure of surface loading on sand using COMSOL, Proceedings of the Second International Conference on Advances in Engineering and Technology, Entebbe, Uganda, (2011).

[9] M.M. Nujid and M.R. Taha, A review of bearing capacity of shallow foundation on clay layered soils using numerical method, Electronic Journal Geotechnical Engineering, 19, 811-825, (2014). 